\title{
Retraction of: Bansal and Arora. J Endourol. Epub ahead of print; DOI: 10.1089/end.2016.0696
}

$\boldsymbol{J}$ OURNAL OF ENDOUROLOGY is retracting the Instant Online (Epub ahead of print) article entitled, "Transurethral resection of prostate and bleeding: A prospective randomized, double blind, placebo controlled trial to see efficacy of short term use of Finasteride and Dutasteride on operative blood loss and prostatic micro-vessel density," by Ankur Bansal and Aditi Arora, DOI: 10.1089/end.2016.0696.

The first author of the article alerted the Editors of Journal of Endourology to the possibility of inaccurate statistics being reported, and as such a new version may be needed. The Editors enlisted the expertise of a statistical reviewer who deemed the manuscript required revision based on the data and analysis provided. In light of this, the original decision to publish the paper has been reversed, and the authors have been instructed to revise the paper based on the statistical review and resubmit it. As a result, the Editors must officially retract the current version. The paper will undergo peer review, and there is no guarantee of its acceptance for publication.

While the author deeply regrets this situation, Journal of Endourology is committed to upholding the strictest standards of peer review and scientific publishing, and officially retracts the article. 